\title{
Magnetic Resonance Guided High-Intensity Focused Ultrasound Mediated Hyperthermia Improves the Intratumoral Distribution of Temperature-Sensitive Liposomal Doxorubicin
}

Citation for published version (APA):

de Smet, M., Hijnen, N. M., Langereis, S., Elevelt, A., Heijman, E., Dubois, L., Lambin, P., \& Grull, H. (2013). Magnetic Resonance Guided High-Intensity Focused Ultrasound Mediated Hyperthermia Improves the Intratumoral Distribution of Temperature-Sensitive Liposomal Doxorubicin. Investigative Radiology, 48(6), 395-405. https://doi.org/10.1097/RLI.0b013e3182806940

Document status and date:

Published: 01/06/2013

DOI:

10.1097/RLI.0b013e3182806940

Document Version:

Publisher's PDF, also known as Version of record

\section{Document license:}

Taverne

\section{Please check the document version of this publication:}

- A submitted manuscript is the version of the article upon submission and before peer-review. There can be important differences between the submitted version and the official published version of record. People interested in the research are advised to contact the author for the final version of the publication, or visit the $\mathrm{DOI}$ to the publisher's website.

- The final author version and the galley proof are versions of the publication after peer review.

- The final published version features the final layout of the paper including the volume, issue and page numbers.

Link to publication

\footnotetext{
General rights rights.

- You may freely distribute the URL identifying the publication in the public portal. please follow below link for the End User Agreement:

www.umlib.nl/taverne-license

Take down policy

If you believe that this document breaches copyright please contact us at:

repository@maastrichtuniversity.nl

providing details and we will investigate your claim.
}

Copyright and moral rights for the publications made accessible in the public portal are retained by the authors and/or other copyright owners and it is a condition of accessing publications that users recognise and abide by the legal requirements associated with these

- Users may download and print one copy of any publication from the public portal for the purpose of private study or research.

- You may not further distribute the material or use it for any profit-making activity or commercial gain

If the publication is distributed under the terms of Article $25 \mathrm{fa}$ of the Dutch Copyright Act, indicated by the "Taverne" license above, 


\title{
Magnetic Resonance Guided High-Intensity Focused Ultrasound Mediated Hyperthermia Improves the Intratumoral Distribution of Temperature-Sensitive Liposomal Doxorubicin
}

\author{
Mariska de Smet, MSc, * Nicole M. Hijnen, MSc, * Sander Langereis, PhD, $\dagger$ Aaldert Elevelt, MSc, $\dagger$ \\ Edwin Heijman, PhD, $\dagger$ Ludwig Dubois, PhD, $\neq$ Philippe Lambin, MD, PhD, $\neq$ and Holger Grüll, PhD*†
}

\begin{abstract}
Objectives: The aim of this study was to investigate the intratumoral distribution of a temperature-sensitive liposomal carrier and its encapsulated compounds, doxorubicin, and a magnetic resonance (MR) imaging contrast agent after high-intensity focused ultrasound (HIFU)-mediated hyperthermiainduced local drug release.

Materials and Methods: ${ }^{111}$ In-labeled temperature-sensitive liposomes encapsulating doxorubicin and $\left[\mathrm{Gd}(\mathrm{HPDO} 3 \mathrm{~A})\left(\mathrm{H}_{2} \mathrm{O}\right)\right]$ were injected intravenously in the tail vein of rats $(n=12)$ bearing a subcutaneous rhabdomyosarcoma tumor on the hind leg. Immediately after the injection, local tumor hyperthermia $(2 \times 15$ minutes $)$ was applied using a clinical 3 T MR-HIFU system. Release of $\left[\mathrm{Gd}(\mathrm{HPDO} 3 \mathrm{~A})\left(\mathrm{H}_{2} \mathrm{O}\right)\right]$ was studied in vivo by measuring the longitudinal relaxation rate $R_{1}$ with MR imaging. The presence of the liposomal carriers and the intratumoral distribution of doxorubicin were imaged ex vivo with autoradiography and fluorescence microscopy, respectively, for 2 different time points after injection ( 90 minutes and 48 hours).

Results: In hyperthermia-treated tumors, radiolabeled liposomes were distributed more homogeneously across the tumor than in the control tumors (coefficient of variation $_{\text {hyp, }, 90 \mathrm{~min}}=0.7 \pm 0.2$; coefficient of variation cntrl, $90 \mathrm{~min}=$ $1.1 \pm 0.2$ ). At 48 hours after injection, the liposomal accumulation in the tumor was enhanced in the hyperthermia group in comparison with the controls. A change in $R_{1}$ was observed in the HIFU-treated tumors, suggesting release of the contrast agent. Fluorescence images showed perivascular doxorubicin in control tumors, whereas in the HIFU-treated tumors, the delivered drug was spread over a much larger area and also taken up by tumor cells at a larger distance from blood vessels.

Conclusions: Treatment with HIFU hyperthermia not only improved the immediate drug delivery, bioavailability, and intratumoral distribution but also enhanced liposomal accumulation over time. The sum of these effects may have a significant contribution to the therapeutic outcome.
\end{abstract}

Received for publication July 5, 2012; and accepted for publication, after revision, November 27, 2012.

From the *Department of Biomedical Engineering, Biomedical NMR, Eindhoven University of Technology; $\dagger$ Department of Minimally Invasive Healthcare, Philips Research Eindhoven, Eindhoven; and $\ddagger$ Department of Radiation Oncology (Maastro), GROW-School for Oncology and Developmental Biology, Maastricht University Medical Centre, Maastricht, the Netherlands.

Conflicts of interest and source of funding: Sander Langereis, Aaldert Elevelt, Edwin Heijman, and Holger Grüll are employed by Philips. Mariska de Smet is currently receiving a grant from the EU FP7 project Sonodrugs (NMP4-LA2008-213706). Nicole M. Hijnen is currently receiving a grant (05T-201) from the Center for Translational Molecular Medicine project VOLTA (CTMM; www.ctmm.nl); Sander Langereis and Aaldert Elevelt, from CTMM project HIFUChem (grant 030-301); and Ludwig Dubois, from CTMM project AIRFORCE (grant 030-103)

M. de Smet and N.M. Hijnen contributed equally to this work.

Supplemental digital contents are available for this article. Direct URL citations appear in the printed text and are provided in the HTML and PDF versions of this article on the journal's Web site (www.investigativeradiology.com).

Reprints: Holger Grüll, PhD, Eindhoven University of Technology, Department of Biomedical Engineering, Biomedical NMR, High Tech Campus 11.p 261, 5656 AE Eindhoven, the Netherlands. E-mail: h.gruell@tue.nl.

Copyright (C) 2013 by Lippincott Williams \& Wilkins

ISSN: 0020-9996/13/4806-0395
Key Words: intratumoral distribution, temperature-sensitive liposomes, highintensity focused ultrasound, hyperthermia, doxorubicin

(Invest Radiol 2013;48: 395-405)

$M$ agnetic resonance (MR)-guided high-intensity focused ultrasound (HIFU) is an emerging noninvasive technology for local thermal therapies in oncology. Magnetic resonance imaging (MRI) provides excellent soft tissue contrast for therapy planning and spatial guidance. ${ }^{1,2}$ In addition, MR allows dynamic mapping of the HIFU-induced temperature change, providing direct feedback to the ultrasound control unit. ${ }^{1-3}$ The latter is a prerequisite for accurate HIFU-induced mild hyperthermia (HIFU-HT) $\left(40^{\circ} \mathrm{C}-42^{\circ} \mathrm{C}\right)$ of tumors over a prolonged period of time. ${ }^{4-6}$ Local mild hyperthermia of tumor tissue in conjunction with chemotherapy and radiotherapy has demonstrated a significant enhancement in the tumor treatment efficacy. ${ }^{7-9}$ The observed synergistic effects are manifold and may originate from an increased blood flow, an enhanced permeability of the tumor (micro)vasculature, and enhanced extravasation of drugs, the expression of heat shock proteins, inhibition of DNA repair, and the stimulation of immune responses. ${ }^{10-16}$ Penetration of small molecular chemotherapeutic drugs to cells at a larger distance from blood vessels is beneficial for the treatment of solid tumors, ${ }^{17-20}$ which potentially could benefit from hyperthermia. Furthermore, liposomal drug formulations benefit from hyperthermia, thanks to an increased extravasation from the vascular compartment into the interstitial space. ${ }^{13,21}$ Besides these synergistic effects in systemic chemotherapy, local hyperthermia has been used to trigger the release of chemotherapeutic drugs from temperature-sensitive liposomes (TSLs). ${ }^{22,23}$ Previous studies have demonstrated that hyperthermia-mediated drug delivery from TSLs resulted in increased drug concentrations in the tumor compared with levels achieved with systemic drug administration or nontemperature-sensitive liposomal drug formulations. ${ }^{24-29}$ The triggered release of drugs from the responsive liposomal formulation makes the drug bioavailable to tumor cells as opposed to the limited bioavailability of drugs that are encapsulated in non-TSLs. ${ }^{30,31}$ Recently, Staruch et $\mathrm{al}^{32}$ demonstrated that the delivery of doxorubicin from TSLs induced by MR-HIFU results in enhanced intracellular uptake of bioavailable drug in heated tumors. Similar results were obtained by Ranjan et al, ${ }^{26}$ showing an increased doxorubicin uptake in the tumor periphery as well as in the tumor core, suggesting an improved intratumoral distribution of the drug. After the application of hyperthermia for 30 minutes, more than $60 \%$ of the injected dox-loaded TSLs was still present in the blood circulation. Their contribution to the overall drug uptake in the tumor over longer times remains unclear, as the effects of HIFU-mediated hyperthermia might show a considerable reminiscence leading to an additional uptake of drugfilled liposomes via the enhanced permeability and retention effect.

Noninvasive MRI and quantification of the drug delivery process have been demonstrated using paramagnetic TSLs coencapsulating drugs and MRI contrast agents (CAs). ${ }^{33-37}$ At hyperthermia, the MRI CA is released from the aqueous lumen of the TSL, resulting 
in a change in the longitudinal relaxation rate $\left(\Delta R_{1}=1 / \Delta T_{1}\right)$, which can be used to probe the drug release. ${ }^{38}$ Temperature-sensitive liposomes loaded with doxorubicin and $\left[\mathrm{Gd}(\mathrm{HPDO} 3 \mathrm{~A})\left(\mathrm{H}_{2} \mathrm{O}\right)\right]$ have shown a good correlation between the MR contrast enhancement and the uptake of doxorubicin in 9L glioma tumors upon MR-HIFU-induced release. ${ }^{36}$

In the work presented here, we designed ${ }^{111}$ In-labeled TSLs encapsulating doxorubicin and $\left[\mathrm{Gd}(\mathrm{HPDO} 3 \mathrm{~A})\left(\mathrm{H}_{2} \mathrm{O}\right)\right]$ for hyperthermiatriggered drug delivery under MR image guidance (Fig. 1). The effect of local MR-HIFU-mediated hyperthermia on the intratumoral distribution of the drug and the liposomal carrier was studied at 90 minutes and 48 hours after intravenous injection. At 90 minutes, a significant fraction of the TSLs is still circulating in the blood, and consequently, the effect of heat-triggered release is measured against passive extravasation of drug-filled liposomes. After 48 hours, the combined effect of heat-triggered release, possible hyperthermia reminiscence, and passive extravasation is obtained.

\section{MATERIALS AND METHODS}

\section{Materials}

1,2-Dipalmitoyl-sn-glycero-3-phosphocholine (DPPC) and hydrogenated- $L-\alpha$-phosphatidylcholine (HSPC) were kindly provided by Lipoid (Ludwigshafen, Germany). 1,2-Dipalmitoyl-sn-glycero-3phosphoethanolamine- $N$-[methoxy(polyethyleneglycol)-2000] (DPPEPEG2000) and cholesterol were purchased from Avanti Polar Lipids (Alabaster, AL). 1,4,7,10-tetraazacyclododecane-1,4,7,10-tetraacetic acid (DOTA)-1,2-Distearoyl-sn-glycero-3-phosphoethanolamine (DSPE) was synthesized according to the procedure described by Hak et al. ${ }^{39}$ Doxorubicin hydrochloride was purchased from AvaChem Scientific (San Antonio, TX). [Gd(HPDO3A) $\left.\left(\mathrm{H}_{2} \mathrm{O}\right)\right]$ (ProHance) was obtained from Bracco Diagnostics (Milan, Italy).

\section{Preparation, Characterization, and Radiolabeling of TSLs}

Temperature-sensitive liposomes were prepared and characterized in a similar fashion as previously described. ${ }^{36}$ DPPC:HSPC:Chol: DPPE-PEG2000:DOTA-DSPE (50:25:15:3:1 molar ratio) were dissolved in a solution of chloroform-methanol ( $4: 1 \mathrm{vol} / \mathrm{vol})$. The organic solvents were removed in vacuo until a thin lipid film was formed, which was further dried overnight under nitrogen flow. The lipid film was hydrated at $60^{\circ} \mathrm{C}$ in $120 \mathrm{mM}\left(\mathrm{NH}_{4}\right)_{2} \mathrm{SO}_{4}$ buffer at $\mathrm{pH} 5.4$ containing $250 \mathrm{mM}\left[\mathrm{Gd}(\mathrm{HPDO} 3 \mathrm{~A})\left(\mathrm{H}_{2} \mathrm{O}\right)\right]$. The suspension was extruded at $60^{\circ} \mathrm{C}$ successively through a polycarbonate filter of $200 \mathrm{~nm}$ ( 2 times) and $100 \mathrm{~nm}$ (6 times). Subsequently, the extraliposomal buffer was replaced by HEPES-buffered saline (HBS) (20 mM HEPES and $137 \mathrm{mM} \mathrm{NaCl}$ at $\mathrm{pH} 7.4$ ) by gel filtration through a PD-10 column. Doxorubicin in HBS $(5 \mathrm{mg} / \mathrm{mL})$ was added to the TSLs at a phospholipid-to-doxorubicin molar ratio of 17.5:1 and the TSLs were incubated at $37^{\circ} \mathrm{C}$ overnight. Finally, the TSLs were passed through a $0.22-\mu \mathrm{m}$ filter and a second PD-10 column to remove any nonencapsulated doxorubicin. The liposomes were concentrated using an Amicon Ultra-4 Centrifugal Filter Unit (100 kDa molecular weight cut off; Millipore).

The hydrodynamic radius of the TSLs was determined in HBS using dynamic light scattering (ALV/CGS-3 Compact Goniometer System; ALV-GmbH, Langen, Germany). The melting phase transition temperature $\left(T_{\mathrm{m}}\right)$ of the liposomal bilayer was determined with differential scanning calorimetry (Q2000; TA Instruments, USA) during heating with $5 \mathrm{~K} / \mathrm{min}$ from $20^{\circ} \mathrm{C}$ to $60^{\circ} \mathrm{C}$. The doxorubicin concentration was determined with a spectrophotometer (Perkin Elmer LS55, $\lambda_{\mathrm{ex}}=485 \mathrm{~nm}$ and $\lambda_{\mathrm{em}}=590 \mathrm{~nm}$ ) in isopropyl alcohol/ $\mathrm{H}_{2} \mathrm{O}(1: 1 \mathrm{vol} / \mathrm{vol})$. The phospholipid concentration was measured by phosphate determination according to Rouser et al. ${ }^{40}$ The gadolinium concentration was determined by inductively coupled plasma-mass spectrometry.
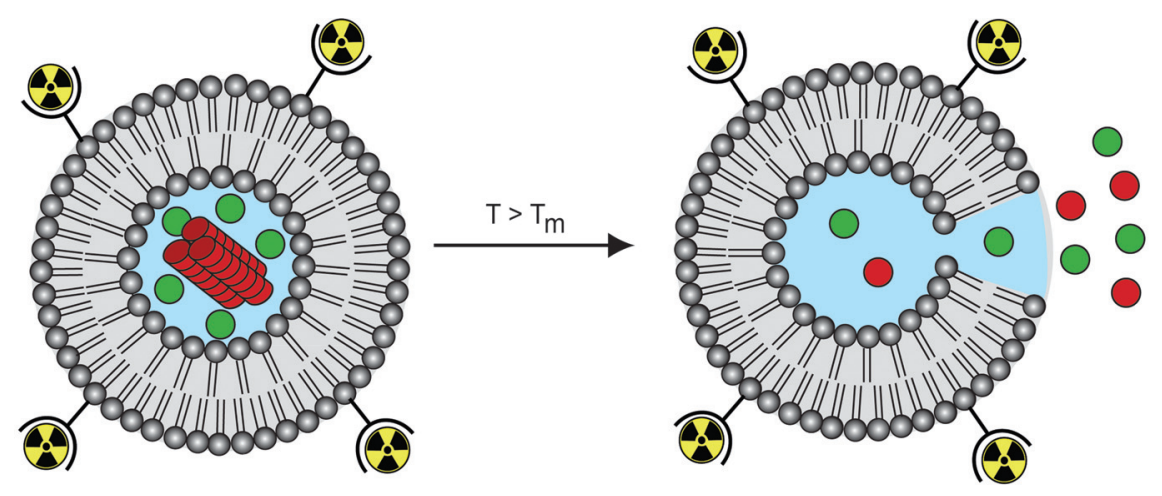

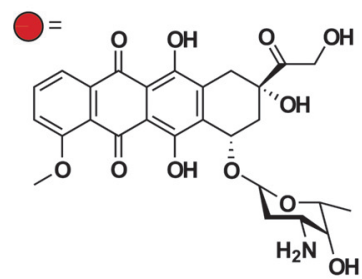

Doxorubicin

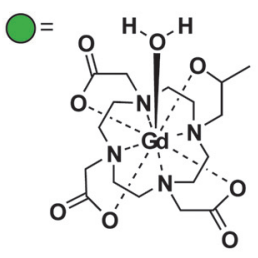

$\left[\mathrm{Gd}(\mathrm{HPDO} 3 \mathrm{~A})\left(\mathrm{H}_{2} \mathrm{O}\right)\right]$

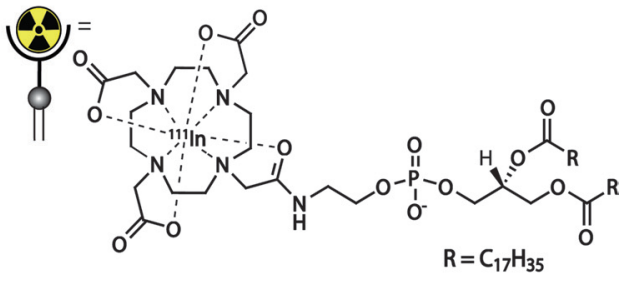

${ }^{111} \operatorname{In}(\mathrm{DOT} A)-\mathrm{DSPE}$

FIGURE 1. ${ }^{111}$ In-labeled TSLs encapsulating doxorubicin and [Gd(HPDO3A)( $\left.\left.\mathrm{H}_{2} \mathrm{O}\right)\right]$. The drug and MRI CA are released from the aqueous lumen at temperatures approaching the melting phase transition temperature of the lipid bilayer. 
Before injection, the TSLs were radiolabeled by overnight incubation at $30^{\circ} \mathrm{C}$ with ${ }^{111} \mathrm{InCl}_{3}$ in $95 \mathrm{mM}$ ammonium acetate buffer at $\mathrm{pH}$ 4.5. The radiolabeling yield was tested with radio-thin layer chromatography (running buffer: $200 \mathrm{mM}$ EDTA in saline) before and after 10 minutes of incubation with $0.1 \mathrm{mM}$ diethylene triamine pentaacetic acid. Subsequently, the sample was passed through a Zeba Desalt Spin column (7 kDa) preequilibrated with HBS ( $\mathrm{pH} 7.4)$, resulting in ${ }^{111} \mathrm{In}$-labeled TSLs with a radiolabeling yield of greater than $95 \%$.

\section{Animal Model}

All preclinical studies were approved by the animal welfare committee of Maastricht University (the Netherlands). The maintenance and care of the experimental animals were in compliance with the guidelines set by the institutional animal care committee, accredited by the National Department of Health. Syngeneic $R_{1}$ rhabdomyosarcoma tumors were established on the hind leg of female Wag/ Rij rats $(n=12)$ (age 5-7 weeks; Charles River) by subcutaneous implantation under anesthesia with pieces of donor tumor tissue $\left(\sim 1 \mathrm{~mm}^{3}\right) .{ }^{41}$ Tumor sizes were determined by measuring the length $(l)$, width $(w)$, and depth $(d)$ using a caliper, and the tumor volume was calculated by $0.5 \times l \times w \times d$. Animal studies were performed with tumor volumes between 300 and $1000 \mathrm{~mm}^{3}$, typically 14 to 20 days after tumor implantation.

\section{MR-HIFU Protocol}

Local hyperthermia of the tumor was performed by MR-HIFU heating in a similar manner as described previously. ${ }^{36,42}$ All animals received Rimadyl (carprofen, $4 \mathrm{mg} / \mathrm{kg}$ body weight) as a precautional pain suppressor before the treatment. Ultrasound gel (Aquasonic 100; Parker Laboratories, Fairfield, NJ) was applied onto the shaven leg and tumor. The animal was placed into a dedicated multichannel small animal MR receiver coil that was used as add-on to a clinical MR-HIFU platform (Philips Sonalleve, Vantaa, Finland). ${ }^{42}$ The respiration rate and body temperature of the animal were monitored continuously. The MR-HIFU platform was integrated into a $3 \mathrm{~T}$ human MR scanner (Philips Achieva, Best, the Netherlands). Subsequently, the treatment was planned on T2-weighted MR images acquired with a turbo spin echo scan (turbo spin echo factor, 7; repetition time [TR]/echo time [TE], 7644/50 milliseconds; field of view [FOV], $40 \times 60 \times 50 \mathrm{~mm}^{3}$; voxel size, $0.5 \times 0.5 \times 0.6 \mathrm{~mm}^{3}$; slices, 20; saturation bands, 2; acquisition time, 1.39 minutes). An ellipsoidal-shaped HIFU treatment cell (diameter $\approx 4 \mathrm{~mm}$, length $\approx$ $10 \mathrm{~mm}$ ) was positioned in the center of the tumor. Several low-power test sonications (continuous wave ultrasound; acoustic frequency, $1.44 \mathrm{MHz}$; acoustic power, 5-10 W; duration, 20 seconds; typical temperature elevation $\approx 1^{\circ} \mathrm{C}-2^{\circ} \mathrm{C}$ ) were performed before therapeutic sonication to correct for possible focus point aberration. During sonication, proton resonance frequency shift-based MR thermometry was used to monitor the temperature change in the target region by continuous acquisition of 1 slice perpendicular and 1 slice parallel to the beam axis, all centered on the target area (RF spoiled gradient echo with EPI readout; flip angle, $19.5^{\circ}$; TR/TE, 52/19.5 milliseconds; EPI factor, 7; SENSE factor, 1.8; FOV, $250 \times 250 \mathrm{~mm}$; matrix, $176 \times 169$; slice thickness, $4 \mathrm{~mm}$; number of averages, 4 ; fat suppression, SPIR; dynamic scan time, 4.8 seconds). For prolonged hyperthermia (acoustic power, $10 \mathrm{~W}$ ), the heating was controlled using a binary feedback control algorithm. ${ }^{5,42}$ A zero-order phase correction was performed for baseline drift correction by subtracting the average phase in a reference region from the MR-acquired phase image, before the calculation of the temperature image.

Maps of the longitudinal relaxation time $\left(T_{1}\right)$ were acquired before and after the two 15-minute hyperthermia treatments, using a single-slice Look-Locker sequence ${ }^{43}$ (flip angle, $10^{\circ}$; TR/TE, 9.0/3.4 milliseconds; interval time, 100 milliseconds; time of inversion repetition, 6 seconds; EPI factor, 5; FOV, $50 \times 69$ mm; matrix, $64 \times 65$; half scan, $80 \%$; slice thickness, $2 \mathrm{~mm}$; number of averages, 2 ; fat suppression, SPIR; acquisition time, 2 minutes 36 seconds). The effective $T_{1}\left(T_{1}{ }^{*}\right)$ was calculated from the signal recovery on a voxelby-voxel basis using an in-house created IDL-based software tool (IDL version 6.3; RSI, Broomfield, CO). Further data processing was performed in MATLAB (R2010a; MathWorks, Natick, MA), in which the longitudinal relaxation rate $R_{1}$ was calculated from the effective $R_{1} *\left(R_{1} *=1 / T_{1} *, R_{1}=R_{1} *+\ln (\cos (\alpha)) / \mathrm{TR}\right.$, with $\alpha=$ $10^{\circ}$ and TR $=100$ milliseconds $)^{44}$ on a voxel-by-voxel basis.

Once the HIFU treatment was planned and coregistered, ${ }^{111} \mathrm{In}$ labeled TSLs $\left(20 \pm 5 \mathrm{MBq}{ }^{111} \mathrm{In}, 0.50 \pm 0.03 \mathrm{~mL}\right)$ were injected via a tail vein catheter at a dose of $5 \mathrm{mg} / \mathrm{kg}$ doxorubicin. Immediately after the injection, the HIFU-induced hyperthermia treatment was started. In the control group, animals received the same handling as the HIFU-treated animals, except for the actual heating. Rats were killed 90 minutes or 48 hours after TSL injection, after which the tumor was dissected. The treatment protocol is shown schematically in Figure 2. The group sizes were $\mathrm{n}=3$ for hyp $90 \mathrm{~min}, \mathrm{n}=4$ for control $90 \mathrm{~min}$, $\mathrm{n}=3$ for hyp $48 \mathrm{~h}$ and $\mathrm{n}=2$ for control $48 \mathrm{~h}$.

\section{Autoradiography}

The activity in the entire dissected tumor was measured using a dose calibrator (VDC-405; Veenstra Instruments). Subsequently, tumor slices of 2-mm thickness were cut from the middle of the tumor using a stainless steel tissue matrix (Ted Pella Inc). Tissue dye was used to mark the tumor, to select the slice corresponding to the middle of the HIFU treatment cell. After weighing, the slices were exposed to a photostimulable phosphor plate for a time varying from 4 hours to 2 days, depending on the amount of radioactivity in the tumor slice. The exposed plates were scanned using a phosphor imager (FLA-7000; Fujifilm). To quantify the homogeneity of the TSL distribution, the coefficient of variation $(\mathrm{CV})$ was calculated of the histogram of pixel intensities from the autoradiographic images. Therefore, regions of interest were manually drawn around the tumor sections (ImageJ; NIH, Bethesda, MD). The CVs between the hyperthermia and control groups were compared statistically using a 2 -sided $t$ test (Statgraphics Centurion, version 16.0.05).

Subsequently, the radioactivity of the tumor slices was quantified using $\gamma$-counting (Wizard 3"; Perkin Elmer). Known volumes of the injected TSLs were counted to serve as reference. The decaycorrected radioactivity in the slices was expressed as a percentage of the injected dose per gram tissue $(\% \mathrm{ID} / \mathrm{g})$.

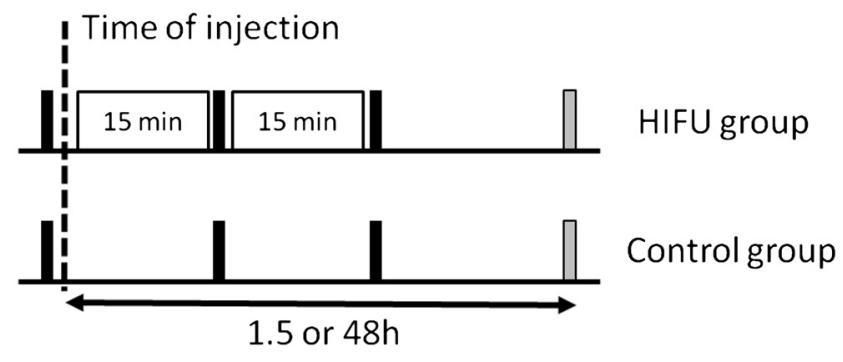

T $\mathrm{T}_{1}$-mapping

HIFU induced hyperthermia

Sacrifice

FIGURE 2. Timelines for the MR-HIFU group and the control experiment (without MR-HIFU). Animals were euthanized either at 1.5 or 48 hours after the administration of the TSLs. 


\section{Histology}

The tumor parts that were not used for autoradiography were snap frozen in 2-methyl butane and stored at $-20^{\circ} \mathrm{C}$ before histological analysis. The frozen tissue was cut into $6-\mu \mathrm{m}$ slices. Fluorescence images of the doxorubicin distribution were acquired with a fluorescence microscope (DM6000B, DFC310FX camera; Leica) equipped with a custom-made doxorubicin filter set (excitation, 480/ $40 \mathrm{~nm}$; emission, 600/60 nm; dichroic, 505lp). Subsequently, the tissue slides were stained with CD31 and DAPI to mark the endothelial cells and cell nuclei, respectively. After fixation with ice-cold acetone $\left(5\right.$ minutes at $\left.-20^{\circ} \mathrm{C}\right)$, the slides were air-dried and washed in PBS. A blocking step was performed with $20 \%$ goat serum in phosphate buffered saline (PBS) containing 1\% bovine serum albumin (BSA) for 15 minutes to minimize nonspecific staining. Primary incubation of mouse monoclonal antirat CD31 antibody (BD Pharmingen) was performed at a dilution of 1:50 in PBS containing 1\% BSA for 2 hours at room temperature. Secondary incubation was performed using antimouse immunoglobulin G-FITC antibody (F5387; Sigma) $(1: 100$ in PBS containing $1 \%$ (BSA) and $5 \%$ goat serum) for 1 hour at room temperature. Finally, the sections were incubated with DAPI (Invitrogen, Molecular Probes) for 10 minutes at room temperature and mounted (Fluoromount F4680; Sigma). Between every step, the sections were washed with PBS. Sections were examined with fluorescence microscopy (filters L5 [FITC] and R/G/B [DAPI]), and the different color channels were merged (ImageJ, http://rsbweb.nih.gov). For anatomical analysis, tissue slides were air-dried briefly at room temperature and stained with hematoxylin and eosin. Cell viability was analyzed after nicotinamide adenine dinucleotide (NADH)-diaphorase staining. For the latter, tissue slides were incubated at $37^{\circ} \mathrm{C}$ for 1 hour in a Gomori-Tris-HCl buffer $(\mathrm{pH} 7.4,10 \mathrm{~mL})$ containing $\beta$-NAD reduced disodium salt hydrate (N8129; $10 \mathrm{mg}$; Sigma-Aldrich, St Louis, $\mathrm{MO}$ ) and nitro blue tetrazolium (N5514; $10 \mathrm{mg}$; Sigma-Aldrich). Specimens were then washed and mounted for analysis with bright field microscopy.

\section{RESULTS}

\section{Radiolabeled TSLS}

Temperature-sensitive liposomes encapsulating doxorubicin and $\left[\mathrm{Gd}(\mathrm{HPDO} 3 \mathrm{~A})\left(\mathrm{H}_{2} \mathrm{O}\right)\right]$ with an average hydrodynamic diameter of $121.8 \mathrm{~nm}$ (polydispersity index $<0.1$ ) have been prepared. The melting phase transition temperature $\left(T_{\mathrm{m}}\right)$, defined as the onset of the phase transition peak in the differential scanning calorimetry thermogram, was $42.4^{\circ} \mathrm{C} \pm 0.1^{\circ} \mathrm{C}$. The phosphorus, gadolinium, and doxorubicin concentrations of the TSL solution were $64.9 \pm 1.8 \mathrm{mM}$, $15.6 \pm 0.8 \mathrm{mM}$, and $3.3 \pm 0.1 \mathrm{mM}$, respectively. The incorporation of $1 \mathrm{~mol} \%$ DOTA-DSPE in the phospholipid bilayer did not affect the stability of the liposomes at $37^{\circ} \mathrm{C}$, nor the doxorubicin release at $42^{\circ} \mathrm{C}$ (Supplemental Figure S1, Supplemental Digital Content 1, http://links.lww.com/RLI/A74). Before injection, the DOTA-functionalized TSLs were labeled with ${ }^{111} \mathrm{In}(41 \pm 10 \mathrm{MBq} / \mathrm{mL})$, resulting in ${ }^{111}$ In-labeled TSLs with a radiolabeling yield of greater than $95 \%$.

\section{MR-HIFU Treatment}

The HIFU-mediated hyperthermia of the tumor was applied immediately after the administration of TSLs. The therapy planning and the temperature maps of the MR-HIFU treatment over time are shown in Figure 3. Although the HIFU treatment cell volume of approximately $85 \mathrm{~mm}^{3}$ was smaller than the tumor volume of approximately $500 \mathrm{~mm}^{3}$, mild hyperthermia of most of the tumor volume was achieved 2 minutes after the onset of HIFU sonication due to heat diffusion (Fig. 3). Furthermore, gradual warming of the muscle surrounding the tumor was observed over time, with some areas reaching similar temperatures as the center of the tumor. During the hyperthermia treatments ( 2 times 15 minutes), the heating was monitored and controlled using a binary feedback control algorithm, obtaining an average temperature in the treatment cell of $41^{\circ} \mathrm{C} \pm 2^{\circ} \mathrm{C}$. Based on previous in vitro measurements, the TSLs are expected to show quantitative release of the encapsulated doxorubicin and $\left[\mathrm{Gd}(\mathrm{HPDO} 3 \mathrm{~A})\left(\mathrm{H}_{2} \mathrm{O}\right)\right]$ within a few minutes at these temperatures. ${ }^{38}$

Maps of the longitudinal relaxation rate $\left(R_{1}\right)$ were acquired before TSL injection and directly after the hyperthermia treatments to probe the release of the MRI CA from the liposomal carrier (Fig. 4). The combination of TSLs and HIFU-induced hyperthermia resulted in an increase in tumor $R_{1}\left(\Delta R_{1 \text {,tumor } 15 \mathrm{~min}}=0.15 \pm 0.10, P=0.022\right.$, 2 -sided paired $t$ test), whereas the $R_{1}$ values of the adjacent muscle remained constant $\left(\Delta R_{1 \text {, muscle } 15 \min }=0.02 \pm 0.07, P=0.628,2\right.$-sided paired $t$ test). The second hyperthermia treatment did not result in a further $R_{1}$ increase $\left(\Delta R_{1, \text { tumor } 30 \mathrm{~min}}=0.15 \pm 0.11, P=0.934,2\right.$-sided paired $t$ test). Control experiments in rats with TSLs without HIFU treatment showed similar $R_{1}$ changes in the tumor as in the surrounding muscle upon injection of the TSLs, suggesting that the liposomal content was not actively released from the TSLs in the unheated tumors. At the end of the protocol (90 minutes or 48 hours after TSL injection), the rats were killed. The tumors were dissected for further analysis using a dose calibrator, autoradiography, and histology.

\section{Autoradiography}

The intratumoral distribution of the ${ }^{111}$ In-labeled TSLs was investigated using autoradiography. Figure 5 shows 1 representative autoradiography image per group. The autoradiography images of all investigated tumor slices, as well as the images scaled to the same $\% \mathrm{ID} / \mathrm{g}$, can be found in the Supplementary Information (Supplemental Figure S2, Supplemental Digital Content 2, http://links.lww.com/RLI/A75). At 90 minutes after injection, the high TSL concentration in the blood ( $>50 \%$ of the injected $\operatorname{dose}^{36}$ ) contributed, to a large extent, to the activity observed on autoradiography. In control tumors, most activity was present in major blood vessels, the tumor rim, and the supporting tissue layer between the skin and the tumor (Fig. 5 and Supplemental Figure S2, Supplemental Digital Content 2, http://links.lww.com/RLI/A75). Table 1 shows the amount of radioactivity in the tumor slices as well as in the whole tumor. At 90 minutes after injection, the ${ }^{111}$ In uptake was not increased because of hyperthermia treatment in comparison with the controls ( $t$ test whole tumor $_{90}$ min hyperthermia vs control: $P=0.684$ ). However, the distribution of radioactivity over the tumor was different, as areas in the core of the heated tumors showed higher uptake (Fig. 5 and Supplemental Figure S1, Supplemental Digital Content 1, http://links.lww.com/RLI/A74). In the hyperthermia-treated tumors, the $\mathrm{CV}$ of the activity distribution was significantly lower than for the control tumors ( $t$ test, $P=0.002$ ), suggesting a more homogeneous activity distribution over the tumors after HIFU hyperthermia treatment. This effect was maintained 48 hours after injection ( $t$ test, $P=0.037$; Supplemental Figure S2, Supplemental Digital Content 2, http://links.lww.com/RLI/A75). After 48 hours, also an activity increase was observed in the hyperthermia group (see Table 1), suggesting that enhanced liposome accumulation and extravasation after the heating have finished.

\section{Histology}

The intratumoral distribution of doxorubicin was examined by fluorescence microscopy. In control tumors $(t=90$ minutes), doxorubicin uptake was visible only in the endothelial cells. For the HIFUtreated tumors, the delivered drug was spread over a larger area (Fig. 6). Furthermore, the doxorubicin was colocalized with tumor cell nuclei, indicating cellular uptake even at relatively large distances $(\approx 50 \mu \mathrm{m})$ from blood vessels. On DAPI (cell nuclei), CD31 (endothelial cell), and hematoxylin and eosin staining, the hyperthermia-treated tumor appeared similar as the control tumor tissue, 


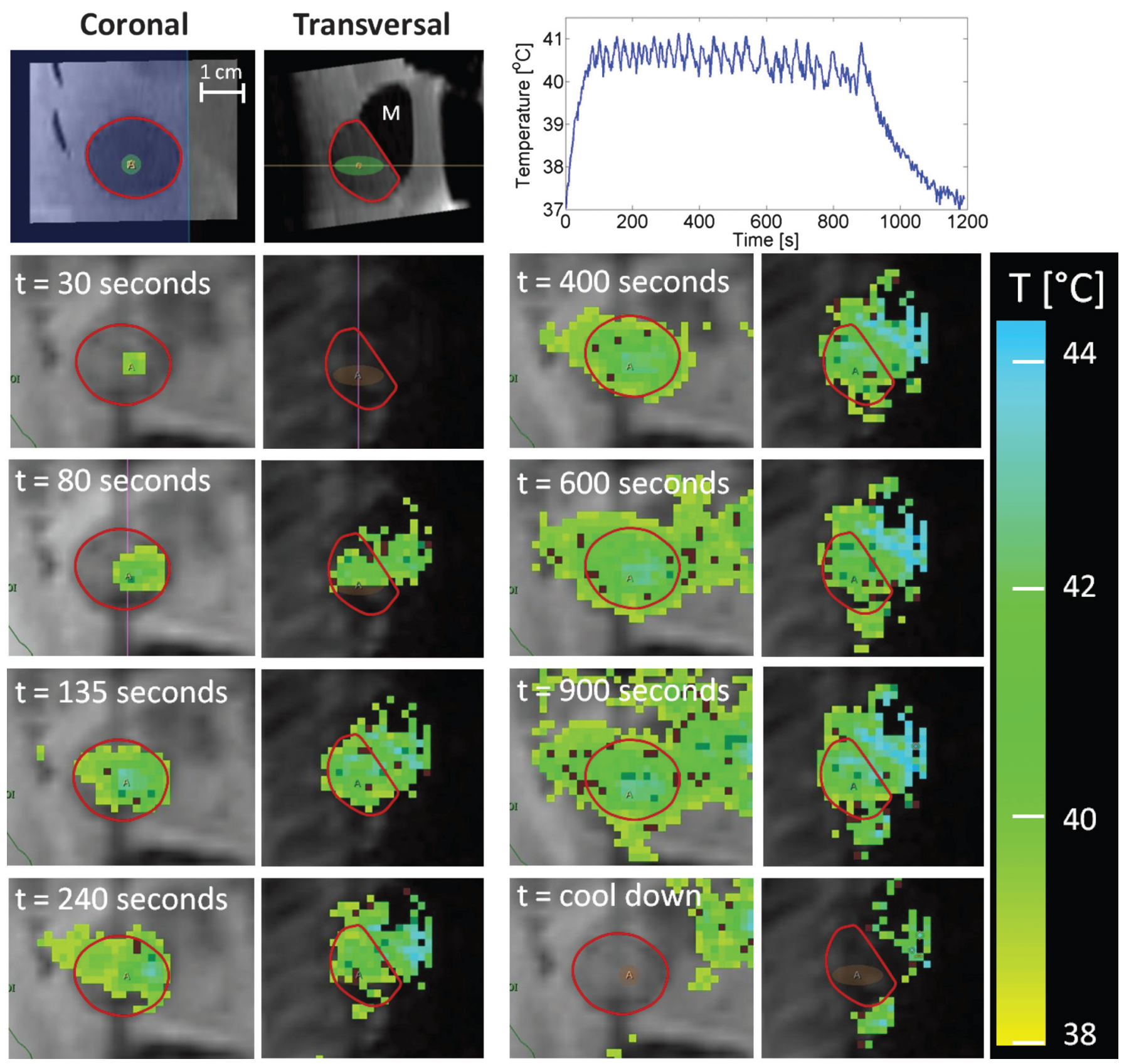

FIGURE 3. MR-HIFU therapy planning and temperature maps. On the top left, anatomical images are shown with an overlay of the planned treatment volume (green ellipsoid). The red contours indicate the tumor area. $\mathrm{M}$ indicates the leg muscle. Temperature maps are shown perpendicular to the ultrasound beam path (left images, coronal) and parallel to the beam path (right images, transversal) over time $(\mathrm{t})$ during hyperthermia treatment. On the top right, the mean temperature of the treatment cell is plotted against time.

showing a tight packing of cell nuclei and a large amount of wellstructured blood vessels distributed over the entire tumor. In both the HIFU-treated and control groups, NADH-diaphorase staining for cell viability showed viable tumor tissue 90 minutes after TSL injection, indicating that there was no instant effect of the therapy on the cell viability.

After 48 hours, cellular uptake of doxorubicin was observed in the control tumors, however to a smaller extent compared with the hyperthermia-treated ones (Fig. 7). In the hyperthermia group, areas that showed a high liposome accumulation on autoradiography also showed high fluorescence on the fluorescence microscopy (Fig. 8).
Interestingly, these areas were congruent with the areas that showed no cell viability on NADH-diaphorase staining. Although a contribution of autofluorescence of necrotic tissue to the signal cannot be fully excluded, the high fluorescent signal observed in this area most likely results from a high doxorubicin uptake. Outside the high-intensity area, the doxorubicin signal was comparable with that in control tumors and viable according to the NADH-diaphorase staining.

\section{DISCUSSION}

In our work, the effect of HIFU-mediated hyperthermia on the intratumoral distribution of TSLs, as well as for the released 


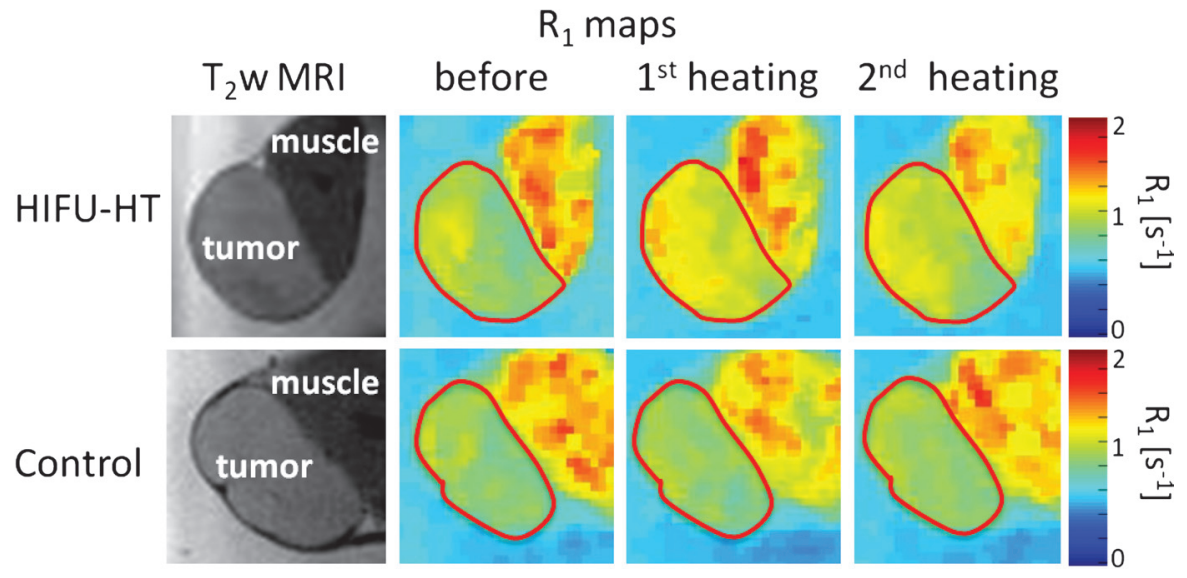

FIGURE 4. T2-weighted MR image and $R_{1}$ maps before TSL injection and after each heating period, with HIFU-mediated hyperthermia (upper row) and control (lower row). No heating was applied for the control tumors; therefore, the $R_{1}$ maps acquired 15 minutes (first heating) and 30 minutes (second heating) after TSL injection are shown. On the $R_{1}$ maps, the tumor is delineated with a red line.

doxorubicin and MRI CA, has been investigated at different time points after injection. The localization of the TSLs and the cellular uptake of doxorubicin were studied using autoradiography and fluorescent microscopy, respectively. Moreover, the in situ release of doxorubicin from the TSLs was probed with MRI by measuring the change in relaxation times induced by the corelease of $\left[\mathrm{Gd}(\mathrm{HPDO} 3 \mathrm{~A})\left(\mathrm{H}_{2} \mathrm{O}\right)\right]$.

Radiographic images of the control tumors showed highest radioactivity along the rim of the tumor, which is usually well perfused or surrounded by large blood vessels. For the MR-HIFUtreated tumors, elevated radioactivity was not restricted to the tumor rim but more spread over the entire tumor. In our previous work, we found more than $50 \%$ of ${ }^{111}$ In-TSLs still being present in the blood circulation after 90 minutes. ${ }^{36}$ Therefore, it is hard to distinguish between tumor uptake of TSLs and liposomes circulating in the blood at this time. However, because the high radioactivity in nonheated tumors coincides with the vascularized tumor rim, the TSLs present in the blood circulation are the most likely explanation for this observation. Although there was no increase in the absolute amount of radioactivity present in the HIFU-treated tumors after 90 minutes compared with control, the activity was distributed differently over the tumor tissue. This suggests a rebalance of perfusion between the tumor periphery and core due to the increased perfusion of the heated tumor areas. The radioactivity was measured in a single slice taken from the tumor center, as well as in the whole tumor volume. Taking into account that more than $50 \%$ of the radiolabeled TSLs are still present in the blood circulation after 90 minutes, the absolute amount of radioactivity is heavily affected by the blood volume distribution in the selected tumor slice. The blood distribution, as well as tumor heterogeneity in general, also explains the difference in absolute activities found in the whole tumors as compared with tumor slices. On the other hand, with less than $5 \%$ of ${ }^{111}$ In-TSLs present in the blood after 48 hours, the autoradiography

$90 \min$ p.i.

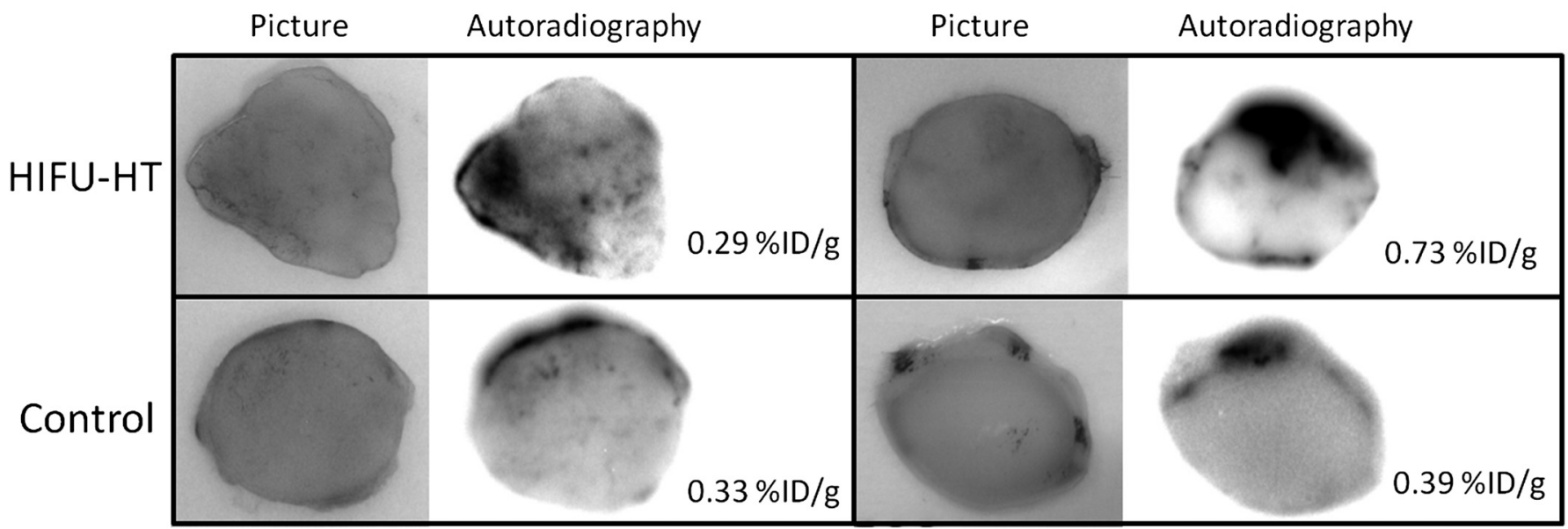

FIGURE 5. Pictures and autoradiography of slices from HIFU-treated and control tumors, 90 minutes and 48 hours after TSL injection. One typical example is shown per group; the results of all measured tumors $(n=12)$ are shown in the Supplementary Information (Supplemental Figure S1, Supplemental Digital Content 1, http://links.lww.com/RLI/A74). The \%ID/g was determined by $\gamma$-counting. Control tumors showed the highest activity in the rim, whereas the HIFU-treated tumors showed a different activity distribution. See Supplementary Information for the corresponding activity profiles. 
TABLE 1. CV and Amount of ${ }^{111}$ In in the Tumor Slice and the Amount of ${ }^{111}$ In in the Whole Tumor for the 4 Groups

\begin{tabular}{lccc}
\hline Group & CV & $\begin{array}{c}\mathbf{1 1 1} \text { In in Tumor } \\
\text { Slice, \%ID/g }\end{array}$ & $\begin{array}{c}\mathbf{1 1 1} \text { In in Whole } \\
\text { Tumor, \%ID/g }\end{array}$ \\
\hline HIFU-HT 90 min & $0.7 \pm 0.2$ & $0.29 \pm 0.01$ & $0.55 \pm 0.31$ \\
Control 90 min & $1.1 \pm 0.2$ & $0.29 \pm 0.08$ & $0.64 \pm 0.24$ \\
HIFU-HT 48 h & $0.6 \pm 0.1$ & $1.42 \pm 0.75$ & $4.21 \pm 1.41$ \\
Control 48 h & $1.4 \pm 0.4$ & $0.48 \pm 0.13$ & $1.99(\mathrm{n}=1)$ \\
\hline
\end{tabular}

images at this time point reflect radiolabeled liposomes accumulated in the tumor. The heated and control tumors after 48 hours showed an increased $\% \mathrm{ID} / \mathrm{g}$ of TSL in comparison with the autoradiographic images at 90 minutes. The ${ }^{111}$ In-TSL accumulation in the MRHIFU-treated tumors was higher in comparison with that in nonheated tumors, which was not yet observed after 90 minutes. These results suggest that HIFU-based hyperthermia has caused longlasting effects, which enhanced liposomal uptake over a much longer time period compared with the hyperthermia treatment itself. These findings are consistent with earlier experiments published by Kong et $\mathrm{al}^{24}$ showing that hyperthermia increases the extravasation of liposomes because of a further enhanced permeability and retention effect in tumors. These effects of hyperthermia on extravasation extended to several hours after administration. As a consequence, doxorubicin levels in the tumor may further increase beyond the amount observed directly after intravascular release triggered by hyperthermia due to further but slow accumulation of drug-filled TSLs that are still circulating. These results are of general importance to applications in liposomal drug delivery because both temperature-sensitive and commercially available non-temperature sensitive liposomal drugs (eg, Doxil, Caelyx) will benefit from the increased extravasation due to HIFU-mediated hyperthermia.

The intratumoral distribution of doxorubicin for the different time points and groups was studied using fluorescence microscopy. At 90 minutes after injection, doxorubicin uptake in HIFU-treated tumors was observed in cells at a much larger distance from blood vessels in comparison with the control tumors, where doxorubicin uptake was visible only in the vicinity of blood vessels. Recently, Manzoor et $\mathrm{al}^{45}$ showed similar results after electric heating in a
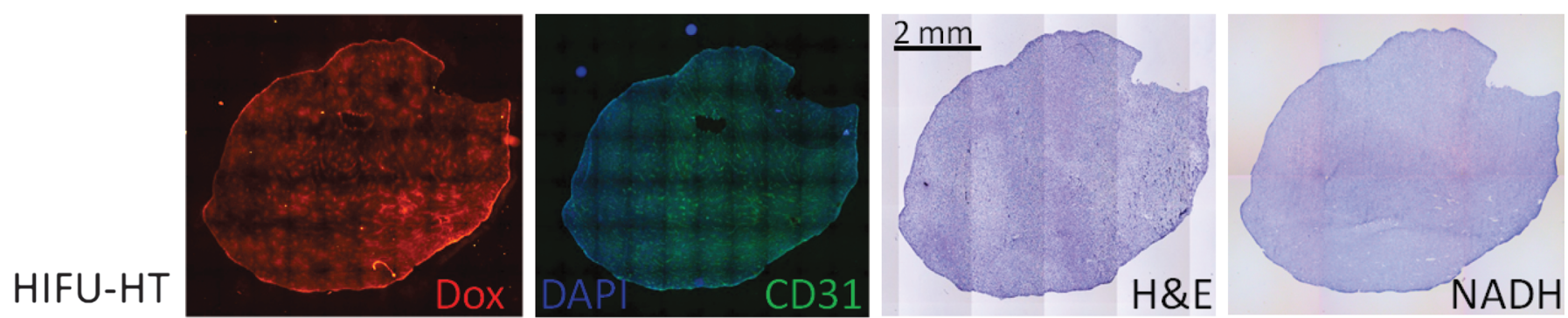

$90 \mathrm{~min}$
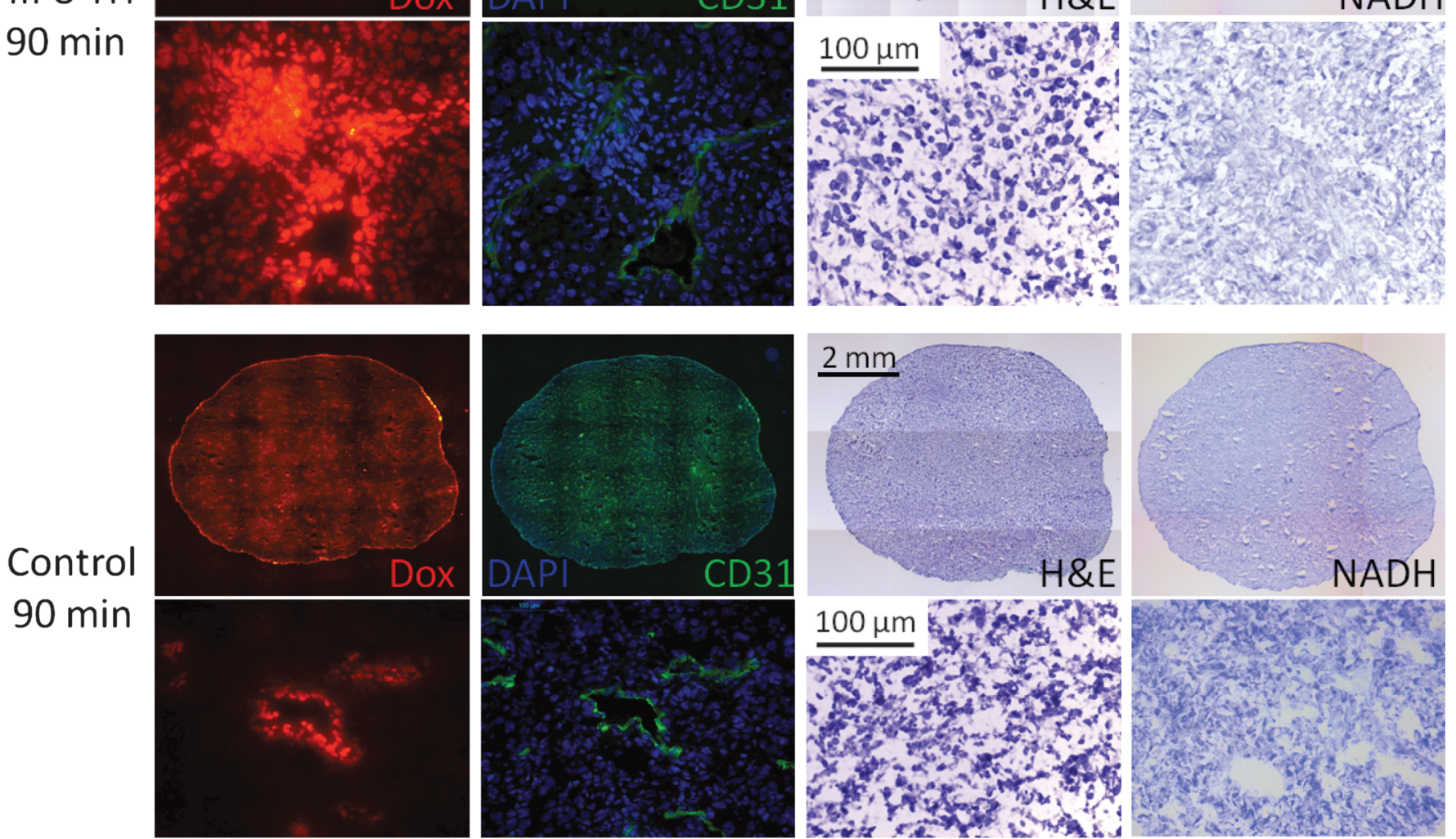

$90 \mathrm{~min}$
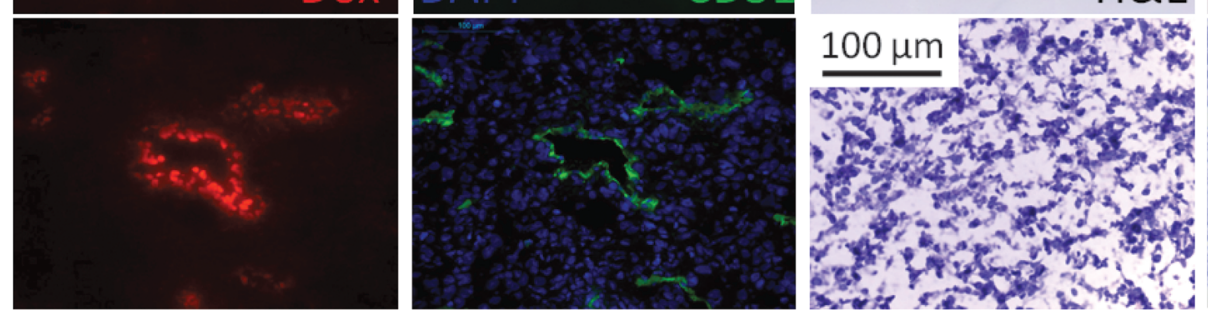

FIGURE 6. Histology of HIFU-mediated hyperthermia-treated and control tumor tissue 90 minutes after TSL injection. Of each staining, an overview image of the whole tumor slice as well as a $\times 40$ zoom is shown. Shutter times for doxorubicin were 3 seconds (overview) and 1 second ( $\times 40$ zoom). On NADH-diaphorase staining, viable cells appear blue, whereas nonviable cells would remain colorless. 
window-chamber model; they observed an increase in drug penetration distance after intravascular release from TSLs. Two days after TSL injection, the doxorubicin was spread throughout the tumor for both the control and HIFU-treated groups. In addition, this observation corresponds with findings from previous studies with non-TSLs, where the drug initially appeared to be restricted to the perivascular space, most likely still encapsulated inside the liposome, but spread throughout the tumor 24 to 48 hours later. ${ }^{46,47}$ The limited bioavailability of the drug at early time points because of slow release from these non-TSLs and the subsequent diffusion-driven distribution across the tumor may be the underlying reason for the observed suboptimal antitumor efficacy in the clinic. ${ }^{48-50}$ In our study, the fluorescence intensity was much higher for the HIFU-treated tumors as opposed to controls, suggesting an increased amount of drug uptake by the heated tumors. Furthermore, doxorubicin becomes directly bioavailable to tumor cells after the temperature-triggered release from the TSLs.
Previously, we have shown that mild hyperthermia of paramagnetic TSLs containing doxorubicin and $\left[\mathrm{Gd}(\mathrm{HPDO} 3 \mathrm{~A})\left(\mathrm{H}_{2} \mathrm{O}\right)\right]$ leads to a simultaneous release of the encapsulated molecules. The change in $R_{1}$ was found to be proportional to the amount of drug delivered in 9L gliosarcoma tumors in rats. ${ }^{36}$ In this study, an increase in the $R_{1}$ was observed immediately after HIFU treatment in a rat rhabdomyosarcoma tumor model, whereas no distinct effect was visible in the control tumor. No further increase in $R_{1}$ was measured after the second hyperthermia treatment, indicating that equilibrium was reached between washout and release of the MRI CA. Overall, the observed $\Delta R_{1}$ due to $\left[\mathrm{Gd}(\mathrm{HPDO} 3 \mathrm{~A})\left(\mathrm{H}_{2} \mathrm{O}\right)\right]$ release from TSLs during HIFU treatment in the rhabdomyosarcoma tumor model was smaller than the effect observed previously in 9L gliosarcoma tumors. ${ }^{36}$ Histological examination of both tumor models showed better structured and more homogeneously formed blood vessels in the rhabdomyosarcoma model in comparison with the 9L tumor (Supplemental Figure S3, Supplemental Digital Content 3,

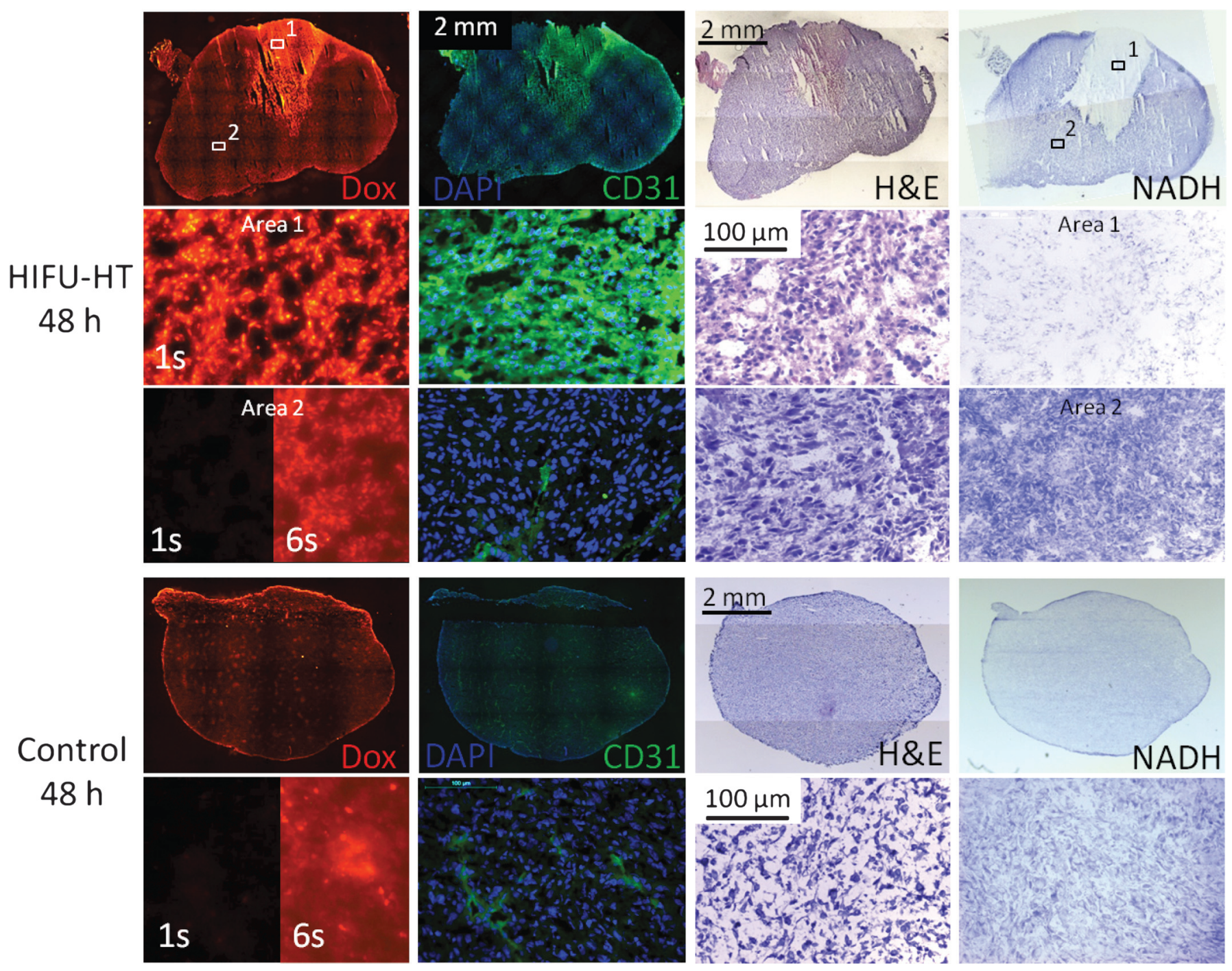

FIGURE 7. Histology of HIFU-mediated hyperthermia-treated and control tumor tissue 48 hours after TSL injection. Shutter times for doxorubicin were 3 seconds (overview) and 1 second ( $\times 40$ zoom). For the control tumor and area 2 of the hyperthermia-treated tumor, the doxorubicin signal intensity was very low. Therefore, images were acquired both with the standard shutter time of 1 second and with a longer shutter time of 6 seconds (indicated in the images). The small boxes indicate where the enlarged images were taken (area 1 and 2). Area 1 shows high signal in the dox channel, as well as in the FITC channel. 
http://links.lww.com/RLI/A76). As expected, the different blood vessel structures also resulted in differences in vessel permeability as measured by dynamic contrast-enhanced MRI, showing $k_{\text {trans }}=0.05$ $\min ^{-1}, k_{\mathrm{ep}}=0.26 \mathrm{~min}^{-1}$, and $v_{\mathrm{e}}=0.21$ for the rhabdomyosarcoma tumor and $k_{\text {trans }}=0.25 \mathrm{~min}^{-1}, k_{\mathrm{ep}}=0.37 \mathrm{~min}^{-1}, v_{\mathrm{e}}=0.66$ for the 9L tumor (Supplemental Figure S4, Supplemental Digital Content 4, $\mathrm{http}: / /$ links.lww.com/RLI/A77). It is important to note that the pharmacokinetic properties of the encapsulated agents before release from the lumen of the TSLs are determined by the liposomal carrier. Upon release, however, the doxorubicin and $\left[\mathrm{Gd}(\mathrm{HPDO} 3 \mathrm{~A})\left(\mathrm{H}_{2} \mathrm{O}\right)\right]$ will show different biodistribution profiles and tumor uptake. The high permeability of doxorubicin across different barriers will result in a rapid distribution in the interstitial space and cellular uptake across the tumor upon its local release. ${ }^{25,45,51,52}$ On the other hand, [Gd(HPDO3A) $\left(\mathrm{H}_{2} \mathrm{O}\right)$ ] will distribute across the extracellular space, ${ }^{53}$ and its intratumoral concentration is a balance between tumor inflow and washout. Therefore, the smaller $\Delta R_{1}$ change observed in the rhabdomyosarcoma model can most likely be explained by the considerably lower $k_{\text {trans }}$ and $v_{\mathrm{e}}$ in this tumor compared with the 9L tumor. Quantitative measurements of the doxorubicin and gadolinium concentrations and a comparison with $\Delta R_{1}$ were not performed in this study because the tumors were used for histology and autoradiography examinations.

As discussed before, mild hyperthermia can be used to improve liposomal chemotherapy in 2 ways. First, hyperthermia leads to an increase in vascular permeability and therefore increasing levels of liposome accumulation, and second, hyperthermia can be used for a triggered drug release from TSLs. ${ }^{54}$ In a recent review by Grüll and Langereis, ${ }^{55}$ studies on MR-HIFU-induced delivery from TSLs have been summarized, reporting a heating-induced 2.3- to 4.9-fold enhancement in tumor doxorubicin concentrations at early time points. This enhancement effect was caused mainly by the intravascular release of doxorubicin during heating. Any additional drug accumulation due to extravasation and uptake of long circulating TSLs and subsequent release of doxorubicin was so far not systematically investigated. Dromi et $\mathrm{al}^{56}$ investigated doxorubicin uptake in tumors at 24 hours after TSL injection followed by pulsed-HIFU exposures. They did not observe a difference between HIFU-exposed and untreated tumors, but this may be attributed to the relatively short exposure of 2 minutes per pulsed-HIFU raster point. Although quantitative measurements of doxorubicin concentrations were not performed in our study, it is quite likely that the measured increase in TSL uptake in heated tumors over 2 days will lead to a further increase in doxorubicin concentrations beyond the level found directly after hyperthermia treatment. In this study, we observed that the HIFU-treated tumors showed necrotic areas at 48 hours after the treatment, corresponding to the areas where large amounts of radioactivity were detected. This observation suggested that the doxorubicin uptake in these areas exceeded the concentrations necessary for cell necrosis. Because no necrosis was detected at 90 minutes after the treatment, it can be assumed that the observed cell death in these tumors was a long-term effect.

In conclusion, MR-HIFU is a promising technology for hyperthermia-induced drug delivery in oncology. Magnetic resonance imaging provides spatial guidance during the planning and treatment as well as accurate temperature feedback to the HIFU transducer. Hyperthermia induced by HIFU was shown to increase drug release from TSLs during hyperthermia and to increase uptake of liposomal

\section{Slice picture}

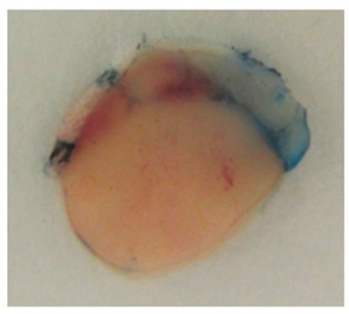

Rat 1

Rat 2
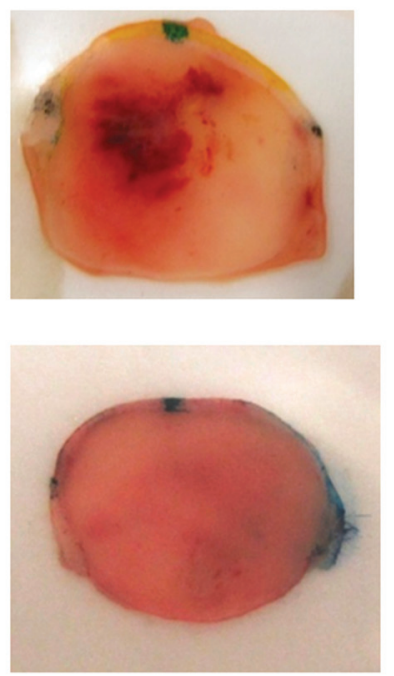

\section{Autoradiography}
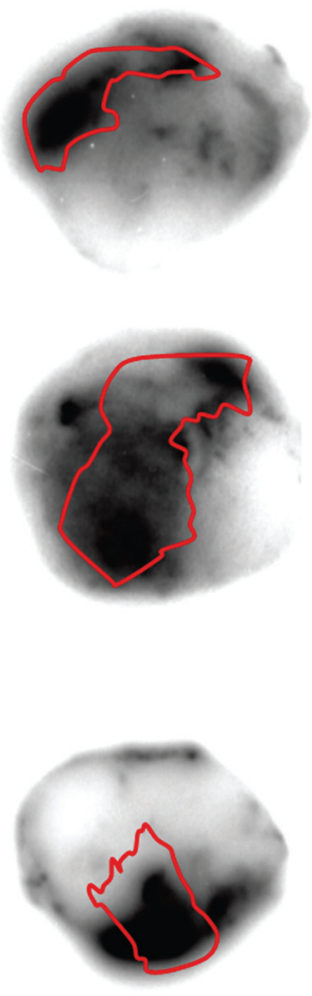
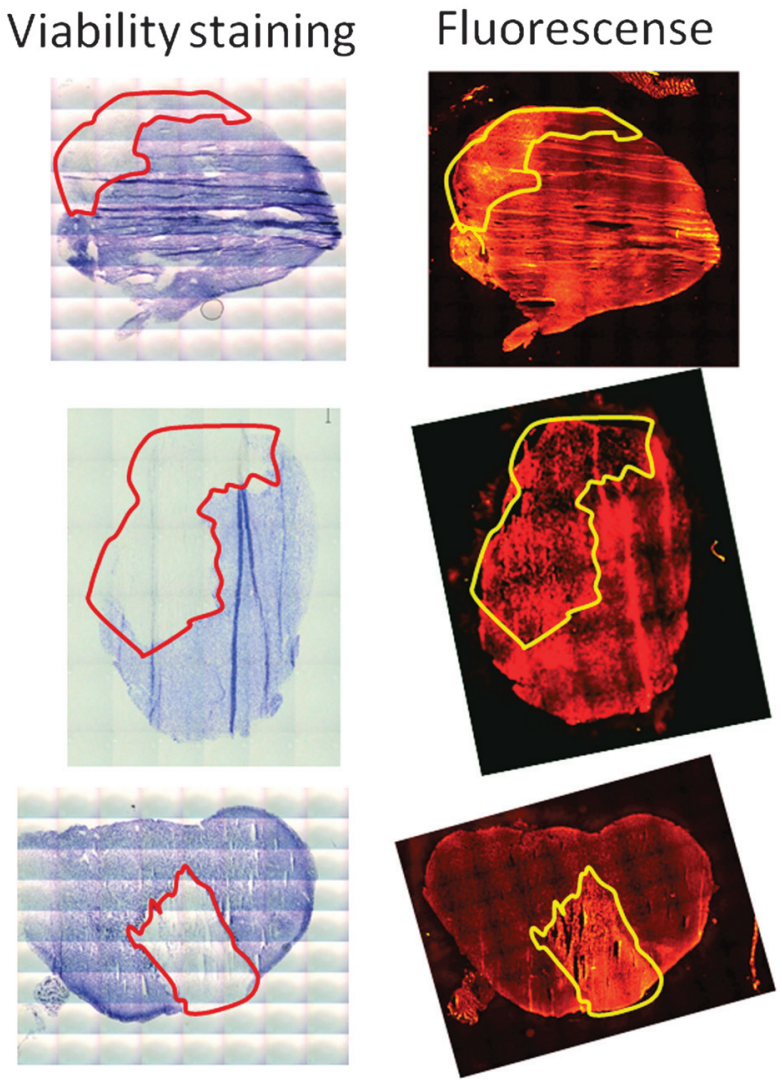

FIGURE 8. Pictures, autoradiography, viability NADH staining, and fluorescence signal intensity in the dox channel of all tumors dissected 48 hours after hyperthermia treatment. The red contour indicates the necrotic area as determined based on the NADH staining, which is overlayed on the autoradiographic image and on the fluorescence image taken from the same histology slice. 
drug delivery carriers in the period after the hyperthermia. In addition, MRI allows to image drug release using TSLs encapsulating MRI CA and doxorubicin. In the hyperthermia group, intravascular release of doxorubicin led to a homogeneous drug coverage of large areas within the tumor. Moreover, liposome accumulation and penetration were increased because of the HIFU hyperthermia treatment. These accumulated liposomes will slowly release the drug throughout the tumor over a longer time period, resulting in even more bioavailable drug present at the tumor site. Both the intravascular release of doxorubicin and the increased accumulation of doxorubicin-filled liposomes may have an important contribution to the therapeutic outcome.

\section{ACKNOWLEDGMENTS}

The authors thank Philips Healthcare (Vantaa, Finland) for all technical support regarding the Sonalleve 3 T MR-HIFU system. They also thank Iris Verel (Philips Research Eindhoven), Caren van Kammen, Carlijn van Helvert, and Melanie Blonk (all Maastricht University) for the support with the animal experiments.

\section{REFERENCES}

1. Cline HE, Hynynen K, Hardy CJ, et al. MR temperature mapping of focused ultrasound surgery. Magn Reson Med. 1994;31:628-636.

2. Ishihara $\mathrm{Y}$, Calderon $\mathrm{A}$, Watanabe $\mathrm{H}$, et al. A precise and fast temperature mapping using water proton chemical shift. Magn Reson Med. 1995;34: $814-823$

3. Hynynen K, Darkazanli A, Unger E, et al. MRI-guided noninvasive ultrasound surgery. Med Phys. 1993;20:107-115.

4. Partanen A, Yarmolenko PS, Viitala A, et al. Mild hyperthermia with magnetic resonance-guided high-intensity focused ultrasound for applications in drug delivery. Int J Hyperthermia. 2012;28:320-336.

5. Enholm JK, Köhler MO, Quesson B, et al. Improved volumetric MR-HIFU ablation by robust binary feedback control. IEEE Trans Biomed Eng. 2010;57:103-113

6. Staruch R, Chopra R, Hynynen K. Localised drug release using MRI-controlled focused ultrasound hyperthermia. Int J Hyperthermia. 2011;27:156-171.

7. Issels RD, Lindner LH, Verweij J, et al. Neo-adjuvant chemotherapy alone with regional hyperthermia for localised high-risk soft-tissue sarcoma: a randomised phase 3 multicentre study. Lancet Oncol. 2010;11:561-570.

8. van der Zee J. Heating the patient: a promising approach? Ann Oncol. 2002;13:1173-1184.

9. Franckena M, Stalpers LJA, Koper PCM, et al. Long-term improvement in treatment outcome after radiotherapy and hyperthermia in locoregionally advanced cervix cancer: an update of the Dutch Deep Hyperthermia Trial. Int J Radiat Oncol Biol Phys. 2008;70:1176-1182.

10. Skitzki JJ, Repasky EA, Evans SS. Hyperthermia as an immunotherapy strategy for cancer. Curr Opin Investig Drugs. 2009;10:550-558.

11. Roti Roti JL. Cellular responses to hyperthermia (40-46 degrees C): cell killing and molecular events. Int J Hyperthermia. 2008;24:3-15.

12. Koning GA, Eggermont AMM, Lindner LH, et al. Hyperthermia and thermosensitive liposomes for improved delivery of chemotherapeutic drugs to solid tumors. Pharm Res. 2010;27:1750-1754.

13. Kong G, Braun RD, Dewhirst MW. Characterisation of the effect of hyperthermia on nanoparticle extravasation from tumor vasculature. Cancer Res. 2001:61:3027-3032.

14. Gaber MH, Wu NZ, Hong K, et al. Thermosensitive liposomes: extravasation and release of contents in tumor microvascular networks. Int J Radiat Onco Biol Phys. 1996;36:1177-1187.

15. Landon CD, Park J, Needham D, et al. Nanoscale drug delivery and hyperthermia: the materials design and preclinical and clinical testing of low temperature-sensitive liposomes used in combination with mild hyperthermia in the treatment of local cancer. Open Nanomed J. 2011;3:38-64.

16. Krawczyk PM, Eppink B, Essers J, et al. Mild hyperthermia inhibits homologous recombination, induces BRCA2 degradation, and sensitizes cancer cells to poly (ADP-ribose) polymerase-1 inhibition. Proc Natl Acad Sci. 2011;108: 9851-9856

17. Tunggal JK, Cowan DSM, Shaikh H, et al. Penetration of anticancer drugs through solid tissue: a factor that limits the effectiveness of chemotherapy for solid tumors. Clin Cancer Res. 1999;5:1583-1586.

18. Tannock IF, Lee CM, Tunggal JK, et al. Limited penetration of anticancer drugs through tumor tissue: a potential cause of resistance of solid tumors to chemotherapy. Clin Cancer Res. 2002;8:878-884.
19. Minchinton AI, Tannock IF. Drug penetration in solid tumours. Nat Rev Cancer. 2006:6:583-592.

20. Primeau AJ, Rendon A, Hedley D, et al. The distribution of the anticancer drug doxorubicin in relation to blood vessels in solid tumors. Cancer Ther. 2005; 11:8782-8788.

21. Kong G, Dewhirst MW. Hyperthermia and liposomes. Int J Hyperthermia. 1999;15:345-370

22. Yatvin MB, Weinstein JN, Dennis WH, et al. Design of liposomes for enhanced local release of drugs by hyperthermia. Science. 1978;202:1290-1293.

23. Weinstein JN, Magin RL, Yatvin MB, et al. Liposomes and local hyperthermiaselective delivery of methotrexate to heated tumors. Science. 1979;204:188-191.

24. Kong G, Anyarambhatla G, Petros WP, et al. Efficacy of liposomes and hyperthermia in a human tumor xenograft model: importance of triggered drug release. Cancer Res. 2000;60:6950-6957.

25. Needham D, Anyarambhatla G, Kong G, et al. A new temperature-sensitive liposome for use with mild hyperthermia: characterization and testing in a human tumor xenograft model. Cancer Res. 2000;60:1197-1201.

26. Ranjan A, Jacobs GC, Woods DL, et al. Image-guided drug delivery with magnetic resonance guided high intensity focused ultrasound and temperature sensitive liposomes in a rabbit Vx2 tumor model. J Control Release. 2012;158: 487-494.

27. Aoki H, Kakinuma K, Morita K, et al. Therapeutic efficacy of targeting chemotherapy using local hyperthermia and thermosensitive liposome: evaluation of drug distribution in a rat glioma model. Int $J$ Hyperthermia. 2004;20: 595-605.

28. Dromi S, Frenkel V, Luk A, et al. Pulsed-high intensity focused ultrasound and low temperature-sensitive liposomes for enhanced targeted drug delivery and antitumor effect. Clin Cancer Res. 2007;13:2722-2727.

29. Gasselhuber A, Dreher MR, Rattay F, et al. Comparison of conventional chemotherapy, stealth liposomes and temperature-sensitive liposomes in a mathematical model. PLoS One. 2012;7:e47453.

30. Laginha KM, Verwoert S, Charrois GJR, et al. Determination of doxorubicin levels in whole tumor and tumor nuclei in murine breast cancer tumors. Clin Cancer Res. 2005;11:6944-6949.

31. Seynhaeve ALB, Hoving S, Schipper D, et al. Tumor necrosis factor alpha mediates homogeneous distribution of liposomes in murine melanoma that contributes to a better tumor response. Cancer Res. 2007;67:9455-9462.

32. Staruch RM, Ganguly M, Tannock IF, et al. Enhanced drug delivery in rabbit VX2 tumours using thermosensitive liposomes and MRI-controlled focused ultrasound hyperthermia. Int J Hyperthermia. 2012;28:776-787.

33. Ponce AM, Viglianti BL, Yu D, et al. Magnetic resonance imaging of temperature-sensitive liposome release: drug dose painting and antitumor effects. J Natl Cancer Inst. 2007;99:53-63.

34. Viglianti BL, Ponce AM, Michelich CR, et al. Chemodosimetry of in vivo tumor liposomal drug concentration using MRI. Magn Reson Med. 2006; 56:1011-1018.

35. Negussie AH, Yarmolenko PS, Partanen A, et al. Formulation and characterisation of magnetic resonance imageable thermally sensitive liposomes for use with magnetic resonance-guided high intensity focused ultrasound. Int $\mathrm{J} \mathrm{Hy}$ perthermia. 2011;27:140-155.

36. de Smet M, Heijman E, Langereis S, et al. Magnetic resonance imaging of high intensity focused ultrasound mediated drug delivery from temperaturesensitive liposomes: an in vivo proof-of-concept study. J Control Release. 2011;150:102-110.

37. Tagami T, Foltz WD, Ernsting MJ, et al. MRI monitoring of intratumoral drug delivery and prediction of the therapeutic effect with a multifunctional thermosensitive liposome. Biomaterials. 2011;32:6570-6578.

38. de Smet M, Langereis S, van den Bosch S, et al. Temperature-sensitive liposomes for doxorubicin delivery under MRI guidance. $J$ Control Release. 2010;143:120-127.

39. Hak S, Sanders HM, Agrawal P, et al. A high relaxivity Gd(III)DOTADSPE-based liposomal contrast agent for magnetic resonance imaging. Eur $J$ Pharm Biopharm. 2009;72:397-404.

40. Rouser G, Fleische S, Yamamoto A. 2 Dimensional thin layer chromatographic separation of polar lipids and determination of phospholipids by phosphorus analysis of spots. Lipids. 1970;5:494.

41. Dubois LJ, Lieuwes NG, Janssen MH, et al. Preclinical evaluation and validation of [18F]HX4, a promising hypoxia marker for PET imaging. Proc Natl Acad Sci U S A. 2011;108:14620-14625.

42. Hijnen NM, Heijman E, Köhler MO, et al. Tumour hyperthermia and ablation in rats using a clinical MR-HIFU system equipped with a dedicated small animal set-up. Int J Hyperthermia. 2012;28:141-155.

43. Look DC, Locker DR. Time saving in measurement of NMR and EPR relaxation times. Rev Sci Instrum. 1970;41:250-251.

44. Shin W, Gu H, Yang Y. Fast high-resolution T1 mapping using inversionrecovery Look-Locker echo-planar imaging at steady state: optimization for accuracy and reliability. Magn Reson Med. 2009;61:899-906.

45. Manzoor AA, Lindner LH, Landon CD, et al. Overcoming limitations in nanoparticle drug delivery: triggered, intravascular release to improve drug penetration into tumors. Cancer Res. 2012;72:5566-5575. 
46. Forssen EA, Malé-Brune R, Adler-Moore JP, et al. Fluorescence imaging studies for the disposition of daunorubicin liposomes (DaunoXome) within tumor tissue. Cancer Res. 1996;56:2066-2075.

47. Uster PS, Working PK, Vaage J. Pegylated liposomal doxorubicin (Doxil®, Caelyx $\left.{ }^{\circledR}\right)$, distribution in tumour models observed with confocal laser scanning microscopy. Int J Pharm. 1998;162:77-86.

48. Judson I, Radford JA, Harris M, et al. Randomised phase II trial of pegylated liposomal doxorubicin (DOXIL $₫ / C A E L Y X ®)$ versus doxorubicin in the treatment of advanced or metastatic soft tissue sarcoma: a study by the EORTC Soft Tissue and Bone Sarcoma Group. Eur J Cancer. 2001;37:870-877.

49. Harris L, Batist G, Belt R, et al. Liposome-encapsulated doxorubicin compared with conventional doxorubicin in a randomized multicenter trial as first-line therapy of metastatic breast carcinoma. Cancer. 2002;94:25-36.

50. O'Brien MER, Wigler N, Inbar M, et al. Reduced cardiotoxicity and comparable efficacy in a phase III trial of pegylated liposomal doxorubicin $\mathrm{HCl}$ (CAELYX ${ }^{\mathrm{TM}} /$ Doxil ${ }^{\circledR}$ ) versus conventional doxorubicin for first-line treatment of metastatic breast cancer. Ann Oncol. 2004;15:440-449.
51. Working PK, Newman MS, Huang SK, et al. Pharmacokinetics, biodistribution and therapeutic efficacy of doxorubicin encapsulated in stealth ${ }^{R}$ liposomes (Doxil®). J Liposome Res. 1994;4:667-687.

52. Harashima H, Iida S, Urakami Y, et al. Optimization of antitumor effect of liposomally encapsulated doxorubicin based on simulations by pharmacokinetic/ pharmacodynamic modeling. J Control Release. 1999;61:93-106.

53. Eakins MN, Eaton SM, Fisco RA, et al. Physicochemical properties, pharmacokinetics and biodistribution of Gadoteridol injection in rats and dogs. Acad Radiol. 1995;2:584-591.

54. Koning GA, Eggermont AM, Lindner LH, et al. Hyperthermia and thermosensitive liposomes for improved delivery of chemotherapeutic drugs to solid tumors. Pharm Res. 2010;27:1750-1754.

55. Grull H, Langereis S. Hyperthermia-triggered drug delivery from temperaturesensitive liposomes using MRI-guided high intensity focused ultrasound. $J$ Control Release. 2012;161:317-327.

56. Dromi S, Frenkel V, Luk A, et al. Pulsed-high intensity focused ultrasound and low temperature-sensitive liposomes for enhanced targeted drug delivery and antitumor effect. Clin Cancer Res. 2007;13:2722-2727. 